RM-75-8

OVERVIEW ON TECHNIQUES AND MODELS

USED IN THE ENERGY FIELD

J.-P . Charpentier

March 1975

Research Memoranda are informal publications relating to ongoing or projected areas of research at IIASA. The views expressed are those of the author, and do not necessarily reflect those of IIASA. 


\section{Overview on Techniques and Models \\ Used in the Energy Field}

J.-P. Charpentier

\section{Introduction}

At the outset, let me comment on the term "models" and on model use. In my view the meaning of the word "model" must be very broad and not confined to econometric approaches. Each tool which could contribute to a better understanding of complex phenomena could receive this designation. But we must not forget that a model as a computer can give no absolute answer; the output must always be related to the input. Models are tools which help the human brain but cannot take its place.

The so-called "energy crisis" has caused increasing concern in the energy industry and in governments. The procedures of environmental protection have further comolicated the energy supply and price picture.

The question of how serious an energy problem we are facing and of alternative strategies can be studied by means of extensive models. The adequacy of the available models and the possibilities of the different kinds of models under development ar are being exhaustively reviewed in most countries. The use of models for decision making in industry is quite well developed, while their use by governments, at national or international levels, is in the beginning stages.

By way of introduction to models in energy, I shall first briefly review the main techniques used in energy modelling to illustrate the extent of the term "model" which ranges from classical methods such as linear programming to the building of normative scenarios. A review of the most important models developed and being developed then follows; and finally, I shall pose some questions linked to a specific problem: the energy demand. 
I. Main Mathematical Techniques Used in Energy Modelling

1.1. Correlation $^{1}$

In the correlation approach one assumes that the objective, for example the energy consumption per capita, is related to a given form such as linear, exponential, and so on, and to a given variable such as income, price, etc. A typical form could be represented by

$$
Q_{t}=K \cdot Q_{t-1}^{a} \cdot Y_{t}^{b} \cdot T_{t}^{c} \cdot p_{t}^{d} \cdot p_{t}^{e},
$$

where

$\mathrm{o}_{t}=$ consumption of a certain kind of energy at time $t$,

$\mathrm{k}=$ constant,

$\mathrm{Y}_{\mathrm{t}}=$ explanatory variable (e.g. GNP, income...),

$\mathrm{T}_{\mathrm{t}}=$ average temperature at time $t$,

$\mathrm{p}_{\mathrm{t}}=$ price of the considered energy,

$\underline{p}_{\hat{t}}=$ price of the concurrent energy,

a) - coefficients estimated by regression on past trend

$\left.\begin{array}{l}\mathrm{b} \\ \mathrm{d}\end{array}\right\}=$ data,

d e - elasticity coefficient as, for example,

$$
b=\frac{\delta \log Q_{t}}{\delta \log Y_{t}},\left\{\begin{array}{l}
\text { elasticity of energy consumption } \\
\text { to the explanatory variable } Y_{t} \\
\text { (if } Y_{t} \text { increases by } 1 \% \text { then } Q_{t} \\
\text { will increase by } \left.b)^{\circ}\right)
\end{array}\right.
$$

The purpose of the method then is to find the best coefficients: $a, b, \ldots, e$, which link the given relation to past data. The method used is the "least square method."

${ }^{1}$ see $[9]$ and $[16]$. 


\begin{tabular}{|c|c|c|}
\hline & \multicolumn{2}{|c|}{$\begin{array}{c}\text { Different variables generally used in regression } \\
\text { analysis }\end{array}$} \\
\hline Sector & $\begin{array}{l}\text { Residential and } \\
\text { Commercial }\end{array}$ & Industrial \\
\hline $\begin{array}{l}0 \\
0 \\
-1 \\
0 \\
\pi \\
-1 \\
4 \\
0 \\
=\end{array}$ & $\begin{array}{l}\text { - Population } \\
\text { - Income per capita } \\
\text { - Prices of the } \\
\text { different fuels } \\
\text { - Weight of each } \\
\text { kind of fuel in the } \\
\text { global consumption } \\
\text { - Quantity of energy } \\
\text { consumed during the } \\
\text { past period }\end{array}$ & $\begin{array}{l}\text { - Number of employees } \\
\text { - Value added } \\
\text { - Prices of the } \\
\text { different fuels } \\
\text { - Weight of specific } \\
\text { sector in the global } \\
\text { industry sector } \\
\text { - Quantity of energy } \\
\text { consumed in the past } \\
\text { period }\end{array}$ \\
\hline
\end{tabular}

I want to emphasize a very important point: the least square method does not permit one to find the most relevant parameters and relationships. It only gives the adjusted coefficient. In order to reach the best relation fitted to the past data it is very important to test different functions.

\section{1.a. Remarks on the Difference between Short- and Long-Term Elasticity ${ }^{2}$}

For simplification, let us suppose that the desired demand of a given form of energy depends on the income and the price:

$$
q_{t}^{*}=k y_{t}^{a} \cdot p_{t}^{b},
$$


where

$$
\begin{aligned}
& \mathrm{q}^{*}=\text { desired quantity } \\
& \mathrm{y}=\text { income, } \\
& \mathrm{p}=\text { price. }
\end{aligned}
$$

The actual level of demand of one year, however, is not necessarily equal to the desired level. In particular, actual demand adjusts toward desired demands according to a linear equation between past consumption and desired demand:

$$
\left\{\begin{array}{l}
\frac{d q_{t}}{q_{t}}=\lambda \frac{d q_{t-1}}{q_{t-1}}+(1-\lambda) \frac{d q_{t}^{*}}{q_{t}^{*}} \\
\Delta \text { demand }=\text { linear combination of }\left(\begin{array}{l}
\text { past } \\
\text { demand }
\end{array}+\begin{array}{l}
\text { desired } \\
\text { demand }
\end{array}\right)
\end{array}\right.
$$

or

$$
q_{t}=q_{t-1}^{\lambda} \cdot\left(q_{t}^{*}\right)^{1-\lambda},
$$

or

$$
q_{t}=\left(\frac{q_{t}}{q_{t-1}^{\lambda}}\right)^{\frac{1}{1-\lambda}} .
$$

If we put (2) in (1), we obtain (3):

$$
\begin{aligned}
\log q_{t}= & A+\lambda \log q_{t-1}+a(1-\lambda) \log y_{t} \\
& +b(1-\lambda) \log p_{t},
\end{aligned}
$$

where

$$
A=(1-\lambda) \log \mathrm{k}
$$


Finally, the elasticity coefficients are:

\begin{tabular}{|c|c|}
\hline \multicolumn{2}{|c|}{ Elasticity coefficients } \\
\hline Short run & Long run \\
\hline$a(1-\lambda)$ & $a$ \\
$b(1-\lambda)$ & $b$ \\
\hline
\end{tabular}

\subsection{Linear Programming}

Most of the models use this well-known technique which consists of optimizing a linear cost function under linear constraints, for example,

$$
\min \sum_{i=1}^{n} c_{i} x_{i} \text {, }
$$

subject to $j$ constraints:

$$
\sum_{i=1}^{n} a_{i j} x_{i} \leq b_{j},
$$

where, for example,

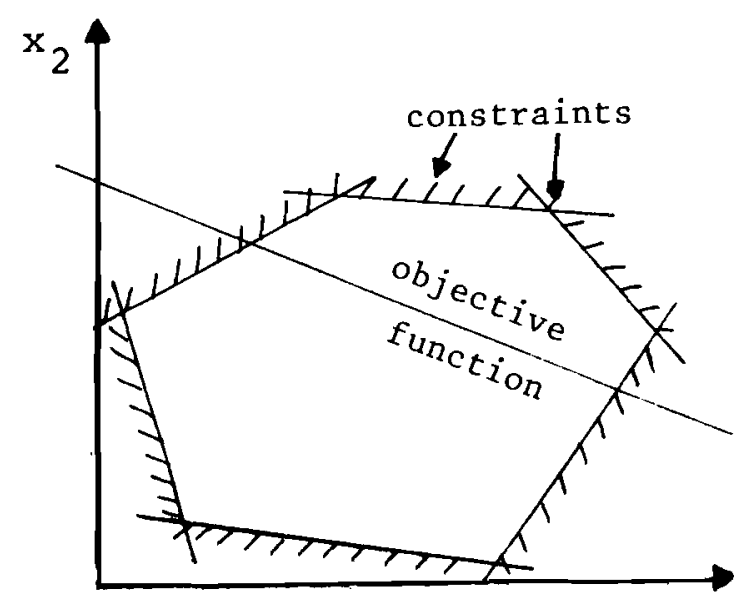

$x_{i}=$ the quantity of energy under the form $i$,

$c_{i}=$ the cost of production of energy $i$.

The $j$ constraints are related to:

- demand to satisfy,

- environmental norms,

- fuel balances,

and so on.

This method could be used for static or dynamic investigations; in this last case, the variables $x_{i}(t)$ and $x_{i}(t+1)$ are considered as two different variables during the programming work. 
The technique of resolution introduces a dual variable $\lambda j$ for each constraint $j$ which (as a Lagrangian multiplicator) ${ }^{3}$ could be interpreted as the marginal cost related to this constraint.

\subsection{Dynamic Programming and Its Derivative}

Each time a decision system could be described at each step $n$ by

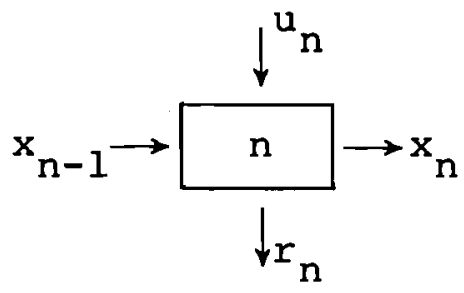

where

$$
\begin{aligned}
& u_{n}=\text { decision variable, } \\
& x_{n}=\text { state variable, } \\
& r_{n}=\text { result variable, }
\end{aligned}
$$

and where the objective function is the sum of the result variable at each step:

$$
\text { Opt } \sum_{n} r_{n},
$$

and where

$$
\begin{aligned}
& r_{n}=R\left(u_{n}, x_{n-1}\right), \\
& x_{n}=x\left(u_{n}, x_{n-1}\right),
\end{aligned}
$$

then the dynamic programming can be used.

For example, see [2] for an investment choice in an electricity utility. This problem could be represented in the following ways:

\footnotetext{
${ }^{3}$ Recal1 Lagrange: solving $\left\{\begin{array}{l}\max f(x) \\ g(x)=0\end{array}\right.$ is the same thing as finding $x$ and $\lambda$ which solve $\max [f(x)+\lambda g(x)]$.
} 

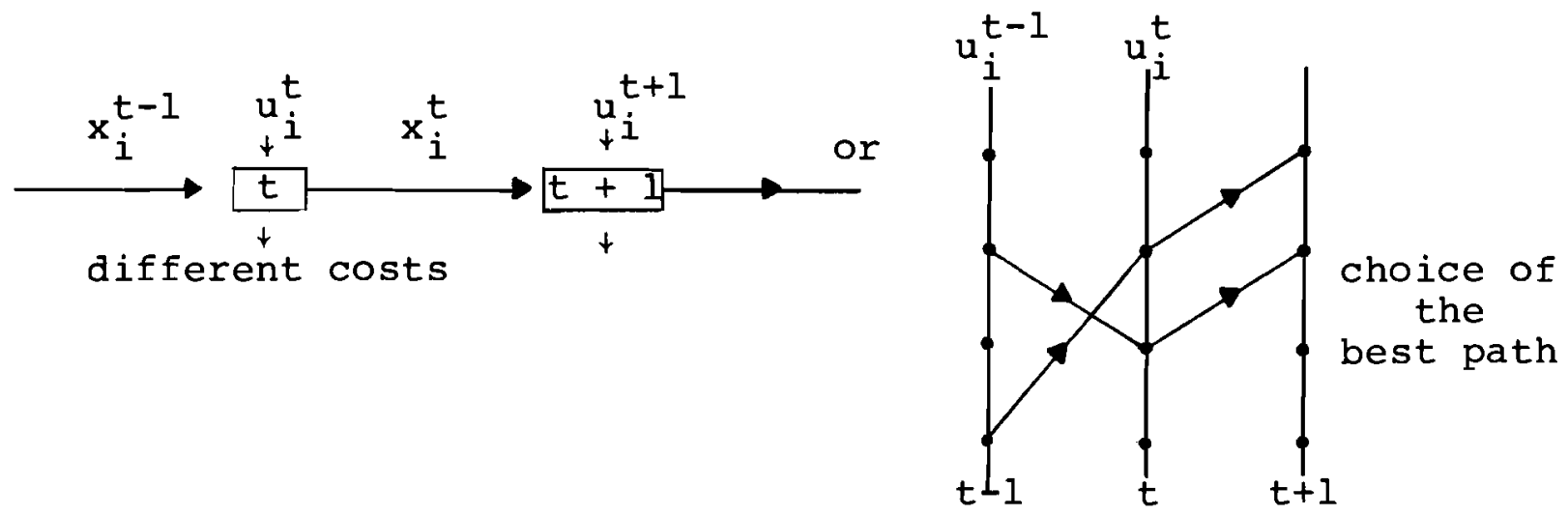

The goal of such a study is to research the optimal investment at each time: $u_{i}^{t} \geq 0$ ( $i$ is the index characterizing each kind of investment: hydraulic, nuclear, different thermic). $x_{i}^{t}$ designates the state variable which corresponds to the global power of the network existing in a plant of type $i$, the year $t$.

The total actualized cost to minimize is

$$
\underset{\substack { t=1 \\
\begin{subarray}{c}{i=1 \\
\text { cost }{ t = 1 \\
\begin{subarray} { c } { i = 1 \\
\text { cost } } } \end{subarray} \sum_{i}^{n} I_{i}^{t} u_{i}^{t}+G^{t}\left(x_{i}^{t}, u_{i}^{t}\right),}{\substack{\text { cost } \\
\text { congement }}}
$$

with the state equation

$$
x_{i}^{t}=x_{i}^{t-1}+u_{i}^{t}, \quad i=1, \ldots, n
$$

(The state of the network at time $t$ equals the state at time ( $t$ - 1) plus the new investment at time $t$. )

1.3.a. Brief Look at the Elementary Mathematical Principle: Dynamic Programming

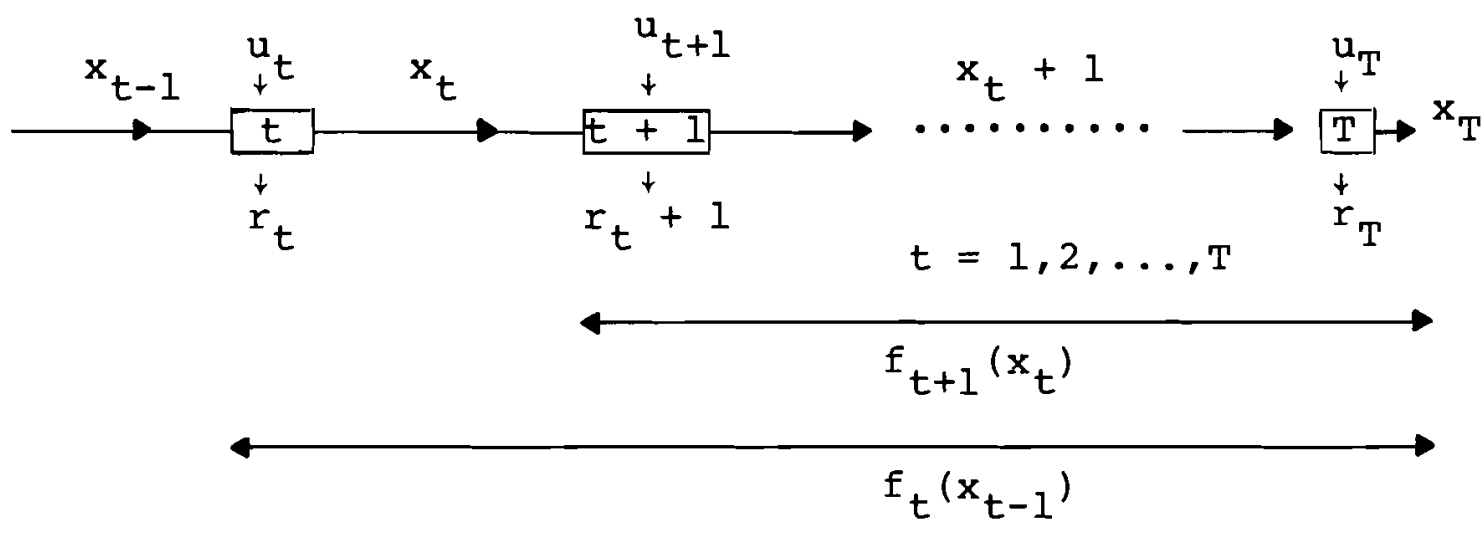


where

$$
\begin{aligned}
u_{t}= & \text { decision variable }\left(u_{t} \varepsilon D\right. \text { : domain of possible } \\
& \text { investments }), \\
x_{t}= & \text { state variable } x_{t}=x\left[x_{t-l}, u_{t}\right], \\
r_{t}= & \text { economic result of the decision } r_{t}=R\left[x_{t-1}, u_{t}\right] .
\end{aligned}
$$

The function to optimize is

$$
\sum_{t=1}^{T} r_{t} \text {. }
$$

In fact, the dynamic programming consists of step by step optimization of the function

$$
f_{t}\left(x_{t-1}\right)=\operatorname{Opt}_{u_{t}}\left[r_{t}+f_{t+1}\left(x_{t}\right)\right]
$$

where $f_{t}$ is optimum from $T$ to $t$. The first steps begin with:

$$
\mathrm{f}_{\mathrm{T}}\left(\mathrm{x}_{\mathrm{T}-1}\right)=\underset{\mathrm{uT}}{\operatorname{Opt}} \mathrm{r}_{\mathrm{T}}
$$

The last steps give the result:

$$
f_{l}\left(x_{0}\right)=\sum_{t} r_{t}
$$

1.3.b. Principle of the "Maximum"

1.3.b.1. Under the Discrete Form

In the maximum principle, the goal is to optimize a linear function of the last state vector:

1) Opt Cx $\left(x_{T}\right.$ as $x_{t}$ could be vectors of $s$ component)

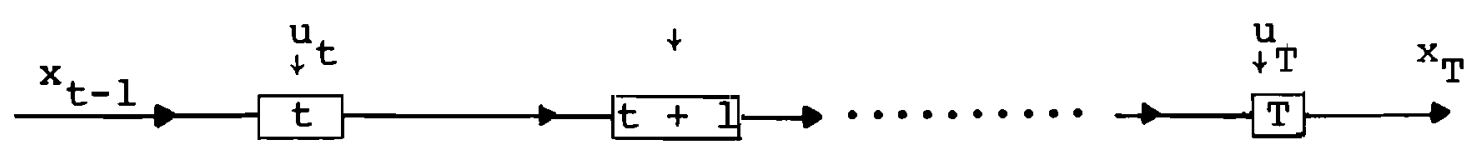


with

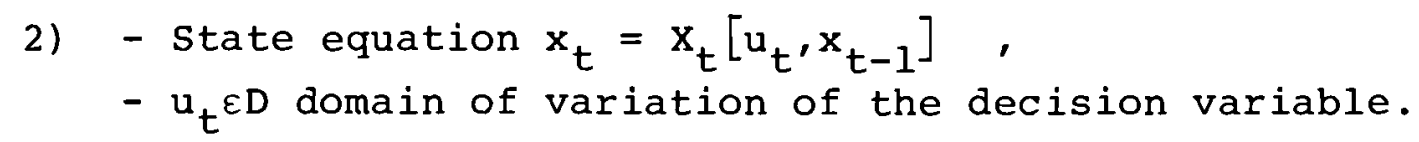

To optimize 1) under 2) is the same as to optimize

3) $\underset{\left(u_{t}, x_{t}\right)}{O p t}=c x_{T}-\sum_{t=1}^{T} \lambda_{t}\left[x_{t}-x_{t}\left(u_{t}, x_{t-1}\right)\right]$,

where $\lambda_{t}$ are the Lagrange multiplicators:

a) optimum related to $u_{t} \frac{\varepsilon D}{}$ : as $u_{t}$ belongs only to one term, it is enough to optimize:

$\hat{\mathrm{H}}_{t}=\lambda_{t} \mathrm{x}_{t}$,

at each step, in function of $u_{t}$;

b) optimum related to $x_{t}$ : as there are no constraints on $x_{t}$ it is possible to derive $L$ at each step.

For the last step,

$$
\frac{\delta \mathrm{L}}{\delta \mathbf{x}_{\mathrm{T}}}=\mathrm{C}-\lambda_{\mathrm{T}} \rightarrow \lambda_{\mathbf{T}}=\mathrm{C}
$$

For each other step (as $x_{t}$ belongs only to $x_{t+1}$ ),

$$
\frac{\delta L}{\delta x_{t}}=-\lambda_{t}+\frac{\hat{H}_{t+1}}{\delta x_{t}} \quad \lambda t=\frac{\hat{H}_{t+1}}{\delta x_{t}} \text {. }
$$

Summary: optimizing $\mathbf{c x}_{\mathrm{T}}$ is equivalent to determining a set of $\lambda_{t}$ which verified:

$$
\begin{aligned}
& \lambda_{T}=c \\
& \lambda_{t}=\frac{\delta \hat{H}_{t+1}}{\delta x_{t}}
\end{aligned}
$$

$\left(\lambda_{t}\right.$ are calculated step after step).

\section{3.b.2. Under the Continued Form (or Maximum Principle of Pontryagin)}

The problem is exactly the same as above. To see roughly how the method goes, let us suppose that the time is divided 
into very small intervals: $\delta$

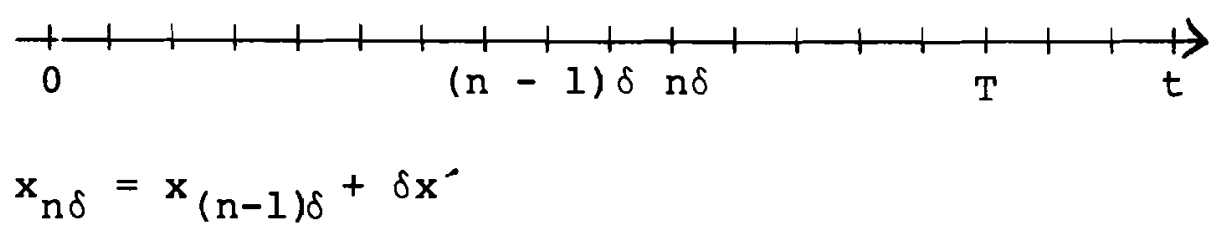

where $x^{\prime}$ is given as:

$$
x^{-}=h\left[x_{(n-1)}, u_{n \delta}\right]
$$

The state variable $x_{n \delta}$ could then be written as before in the discrete case:

$$
x_{n \delta}=x_{(n-1) \delta}+\delta h=x_{n \delta}\left[u_{n \delta}, x_{(n-1) \delta} \mid\right.
$$

Then the problem is close to the discrete case, and it is easy though lengthy to show that the solution of the problem is to find the vector $\lambda(t)$ where

$$
\begin{aligned}
& \text { Opt } \hat{H}=\underset{u(t)}{O \text { Opt }} \lambda(t) \cdot h(x, u) \\
& \frac{d}{d t} \cdot \lambda(t)=-\frac{\delta h}{\delta x(t)} \cdot \lambda(t)
\end{aligned}
$$

\section{Economic Interpretation}

$\lambda(t)$ could be interpreted as the maximum price for the state variable that the owner of the system would accept marginally to pay for getting it on an external market, if this would exist.

\subsection{Simulation}

In this case it is impossible to give a general overview of the mathematical technique. There is no function to optimize. Each author mathematically describes the system he wants to study, and he does so after sensitivity studies of the different parameters. 
It is nevertheless interesting' to note one kind of simulation which consists in simulating a system at the supposed optimum level and for doing so to use the equations of the optimum condition. Let us briefly recall what these conditions (called Kuhn and Tucker conditions) are. When the system

$$
\begin{gathered}
\operatorname{Max} Y(x) \\
a(x) \geq 0
\end{gathered}
$$

is optimum, then a vector $u \geq 0$ exists, with

$$
\begin{aligned}
& \left(\frac{d Y}{d x}\right)_{\hat{x}}+u\left(\frac{d a}{d x}\right)_{\hat{x}}=0, \\
& u a(\hat{x})=0,
\end{aligned}
$$

where

$$
\begin{aligned}
& \mathrm{Y}=\text { the objective function, } \\
& \mathrm{a}(\mathrm{x})=\text { the matrix of conditions, } \\
& \mathrm{u}=\text { vector of dual variables that could often be } \\
& \quad \text { interpreted as marginal costs. }
\end{aligned}
$$

For example, Prof. Hendrick Houthakker and Michael Kennedy at Harvard [11] used this technique to simulate world uses of petroleum where each of the equations used has an economic interpretation:

- one postulates that the supply of crude oil and the demand for products in each region depends linearly on all prices in the world market;

- another translates the fact that the cost for operating any activity must be less than or equal to the revenue of operating this activity, and so on.

\subsection{Other Different Techniques}

1.5.a. Input-Output Analysis

Robert Herendeen [8] has been one of the first to develop the relationship between energy consumption and the money 
value of the output of different sectors of the industry. This technique is based on I/O matrices that we can describe in the following linear form:

$$
x_{i}=\sum_{j=1}^{n} A_{i j} x_{j}+y_{i}
$$

where

$$
\begin{aligned}
& \mathrm{X}_{i}=\text { the total output (dollars) of sector } i \\
& Y_{i}=\text { the output (dollars) of } i \text { sold to final demand }
\end{aligned}
$$

$A_{i j}=$ the constant coefficient representing what the sector $i$ sells to the sector $j$ for producing one unit of its output.

Equation (4) can be put in the matrix form

$$
X=A X+Y,
$$

or

$$
X=(I-A)^{-1} Y
$$

Herendeen introduces the energy in the following way: Let

$$
E_{i}=\sum_{k=1}^{n} E_{i k}+E_{i y},
$$

where

$$
\begin{aligned}
& E_{i}=\text { total energy output (Kcal) of energy sector } i, \\
& E_{i k}=\text { energy sales (Kcal) from sector } i \text { to } k, \\
& E_{i y}=\begin{array}{l}
\text { energy sales (Kcal) from sector } i \text { to final } \\
\text { users, }
\end{array}
\end{aligned}
$$

since

$$
E_{i k}=\left(\frac{E_{i k}}{X_{k}}\right) x_{k}=\left(\frac{E_{i k}}{X_{k}}\right) \sum_{\ell=1}^{n}\left[(I-A)^{-l}\right]_{k \ell} Y_{\ell},
$$




$$
E_{i}=\sum_{k=1}^{n} \sum_{\ell=1}^{n} \frac{E_{i k}}{X_{k}}\left[(I-A)^{-1}\right]_{k \ell} Y_{\ell}+\left(\frac{E_{i y}}{Y_{i}}\right) Y_{i} .
$$

Define

$$
\begin{aligned}
& \text { a) } R_{i k}=E_{i k} / X_{k}, \\
& \text { b) } s_{i k}= \begin{cases}E_{i y} / y_{i}, \quad i=k=\text { energy sector. } \\
0, \text { otherwise. }\end{cases}
\end{aligned}
$$

Then

$$
E=\left[R(I-A)^{-1}+S\right] Y=\sum Y
$$

where $\sum$ is the total energy matrix. $\sum_{i j}$ gives the total output (Kcal) of energy sector $i$ required for the economy to deliver a dollar's worth of project $j$ to final demand. For an example from the glass sector, ${ }^{4}$ see Figure 1 .

\section{5.b. Scenarios ${ }^{5}$}

Each model, in fact, represents a fixed scenario, and therefore it is necessary to explain what we here call a "scenario". This term indicates the description of different states of the world through the aggregation of elementary events.

In order to be clearer let us take an example: suppose that in order to describe the energy situation related to the forthcoming period 1975-1990 we consider the different situations obtained by combination of the following three simple events:

1) the first event will belong to the technical area as $e_{1}$ : 758 of electricity is supplied by nuclear plants;

2) the second event will belong to the environmental area as $e_{2}$ : on the average, all the rivers of the country will be at $30^{\circ} \mathrm{C}$.

${ }^{4}$ Unpublished study made at IIASA with the French I/O table for 1969 .

${ }^{5}$ For more details see J.C. Duperrin and M. Godet, [5] and [6]. 


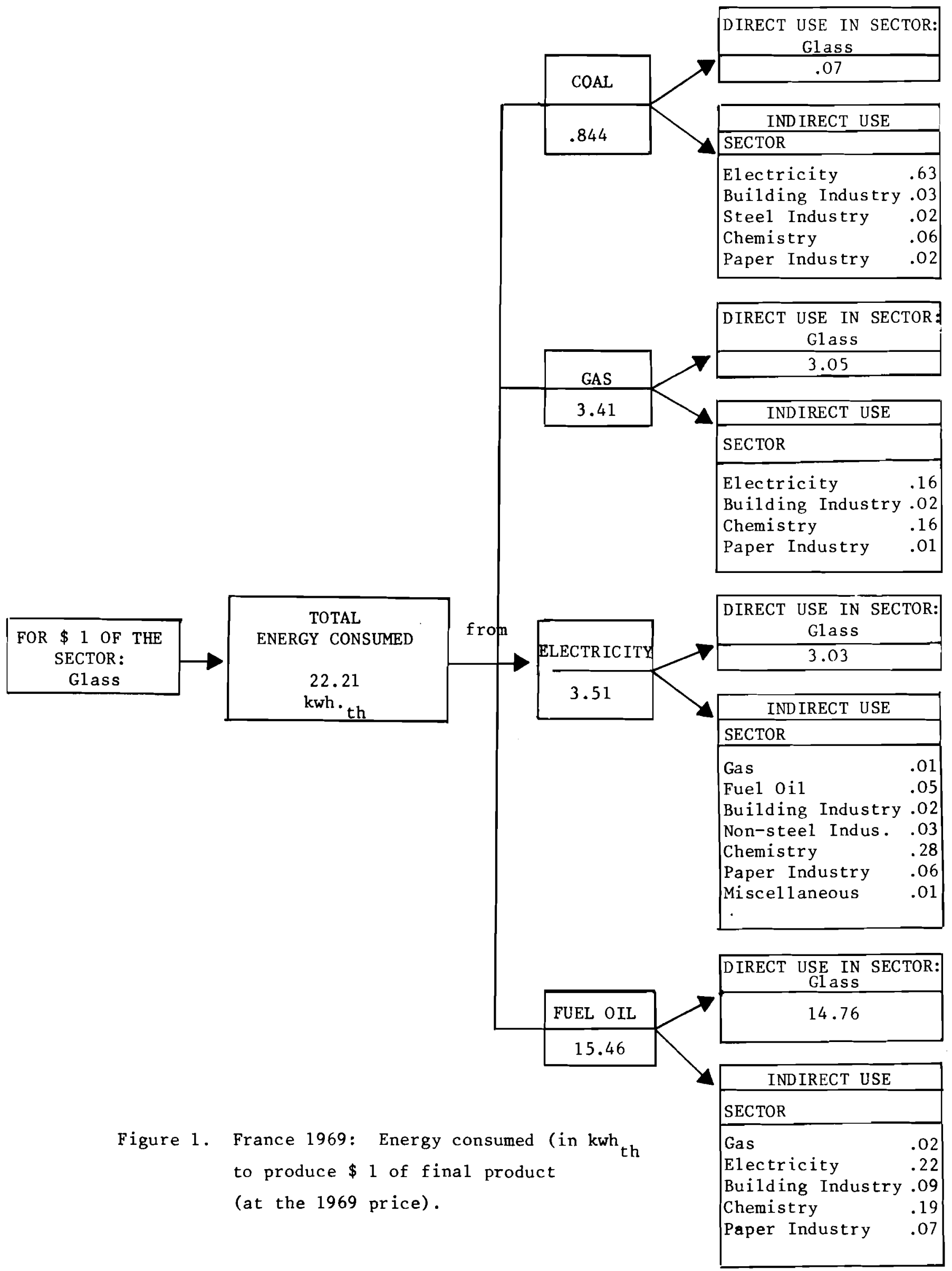


3) the last event will belong to the sociological area as $e_{3}$ : each year there are stong protest marches against nuclear power plants.

A scenario on a state of the world could be supplied by the combination of the three elementary events, e.g.

$$
s_{i}=\left\{e_{1}, \bar{e}_{2}, \bar{e}_{3}\right\}\left\{\begin{array}{l}
\text { Nuclear power supplies } 75 \% \text { of the } \\
\text { electricity, but technical progress } \\
\text { has been made in the cooling system } \\
\text { and there is no risk of strong opposition } \\
\text { to nuclear energy; }
\end{array}\right.
$$

or

$$
s_{j}=\left\{\bar{e}_{1}, e_{2}, \bar{e}_{3}\right\}\left\{\begin{array}{l}
\text { Nuclear power does not supply } 75 \% \text { of the } \\
\text { electricity but nevertheless, for } \\
\text { other reasons, the temperature of the } \\
\text { rivers is at } 30^{\circ} \mathrm{C} \text { and there is no } \\
\text { opposition to nuclear energy; }
\end{array}\right.
$$

and so on. On the whole it is possible in this case to build $2^{3}=8$ scenarios. If the number of elementary events was fifty, it would be possible to build $2^{50}$ scenarios. As it is impossible to study a great number of scenarios, it is best to study only the most relevant ones. To do so, the idea is to classify the different scenarios in a stochastic order. It is roughly possible to do the following. Ask a panel of experts to reach a consensus in regard to the following probabilities:

$$
\begin{aligned}
& \mathrm{p}(i)= \text { probability that the event } e_{i} \text { will occur during } \\
& \text { the considered time period } 1975-1990, \\
& \mathrm{p}(i / j)= \text { probability that } e_{i} \text { will occur, given that } e_{j} \\
& \text { has occurred in this period, } \\
& \mathrm{p}(i / \bar{j})= \text { probability that } e_{i} \text { will occur, given that } e_{j} \\
& \text { has not occurred during this time period. }
\end{aligned}
$$

These probabilities only concern either separate events or pairs of events but, nevertheless, it would be very suprising if the experts' opinions would satisfy the classical 
relationship

$$
\left\{\begin{array}{l}
p(i)=p(i / j) \cdot p(j)+p(i / \bar{j}) \cdot p(\bar{j}) \\
p(i \cdot j)=p(i / j) \cdot p(j)=p(j / i) \cdot p(i)
\end{array} .\right.
$$

Furthermore, the information is not sufficient to calculate the probability of each state of the world:

$$
E_{k}=\left\{e_{1}, e_{2}, \ldots, e_{n}\right\}
$$

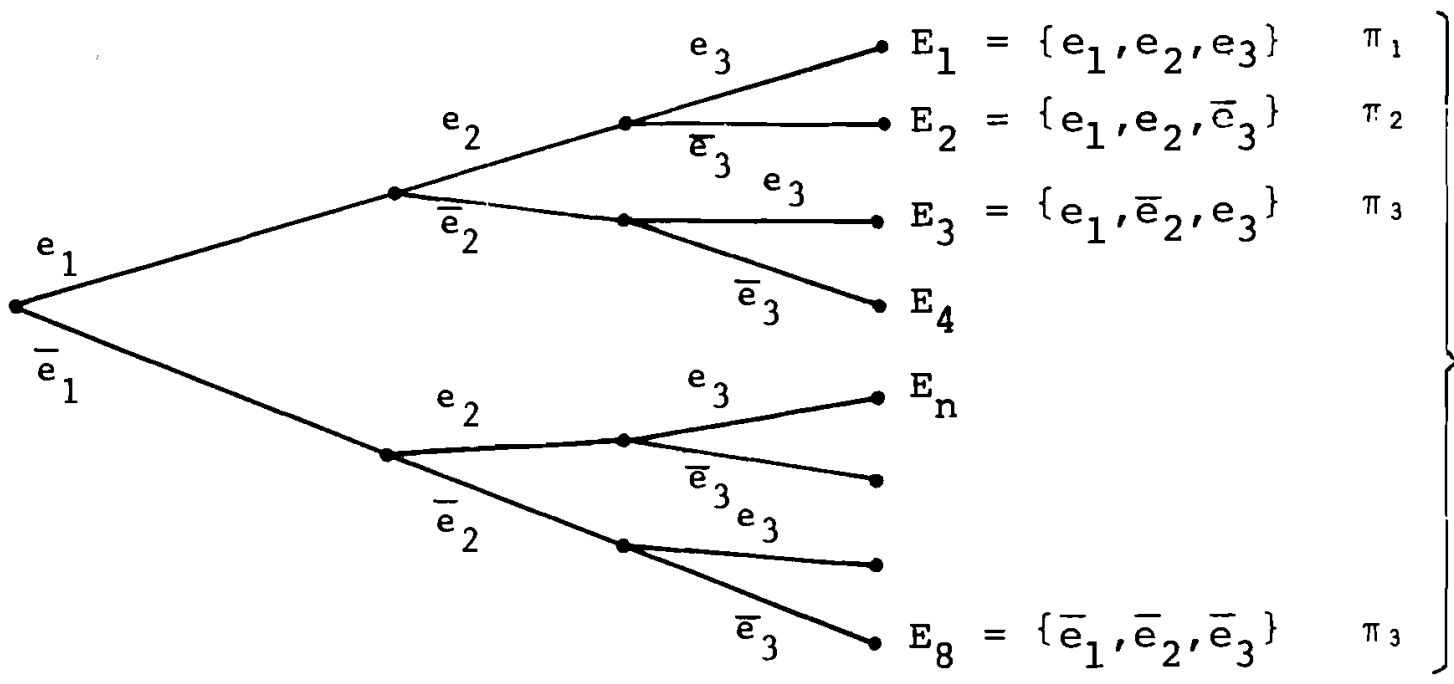

Let us call $\Pi_{k}$ the unknown probability of the state of the world $E_{k}\left(\sum_{k} \Pi_{k}=1\right)^{k}$. Then the probability of a simple event $e_{i}$ can be written in the following form:

$$
p^{*}(i)=\sum_{k=1}^{2^{N}} \theta_{i k} \cdot \Pi_{k} \text {, }
$$

where

$$
\begin{aligned}
& \theta_{i k}=0, \text { when } e_{i} \text { does not belong to } E_{k^{\prime}} \\
& \theta_{i k}=1 \text {, when } e_{i} \text { belongs to } E_{k} \text {. }
\end{aligned}
$$

In the same way

$$
p^{*}(i / j)=\frac{\sum t(i j k) \Pi k}{p(j)},
$$


where

$$
\begin{aligned}
& t(i j k)=1, \text { when } e_{i} \text { and } e_{j} \text { belongs to } E_{k^{\prime}} \\
& t(i j k)=0, \text { when } e_{i} \text { or } e_{j} \text { does not belong to } E_{k} \text {. }
\end{aligned}
$$

And

$$
p^{*}(i / \bar{j})=\frac{\sum^{k} s(i j k) \pi k}{1-p(j)}
$$

where

$$
\begin{aligned}
& S(i j k)=1, \text { when } e_{i} \text { and } \bar{e}_{j} \text { belongs to } E_{k} \text {, } \\
& S(j j k)=0
\end{aligned}
$$

The $\mathrm{D}^{*}$ stars are theoretical probabilities which satisfied the relations (5). The probabilities of each state of the world $\Pi_{k}$ will be found in minimizing the difference between $p(i) \cdot p(i / j)$ factors resulting from the experts' opinions and the theoretical probability $p^{*}(i) \cdot p^{*}(i / j)$ expressed in terms of $\Pi_{\mathrm{k}}$.

The objective function is:

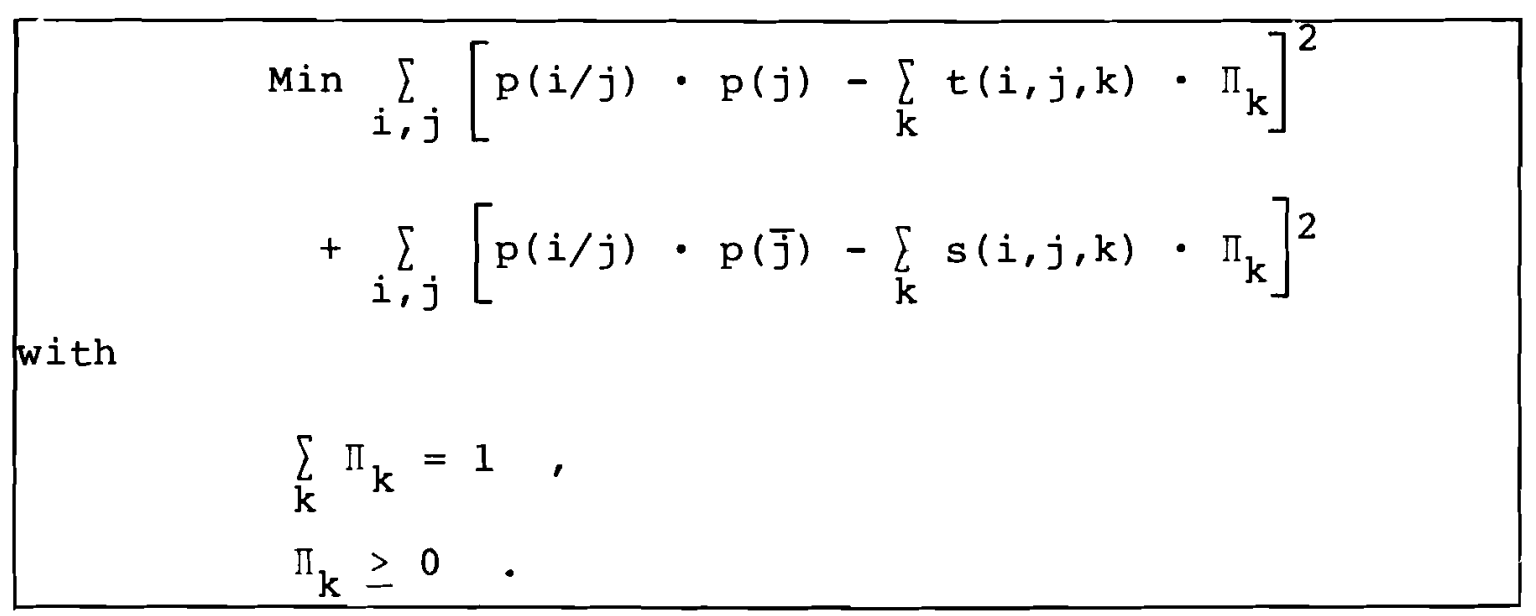

The output of the program (9) gives the probability $\pi_{k}$ of each state of the world and an a posteriori probability $p^{*}$ of the experts' opinions in using the relations $(6),(7)$, and (8). 
It is then possible to classify the states of the world and to study only the most relevant ones. This approach could be summarized in the following way:

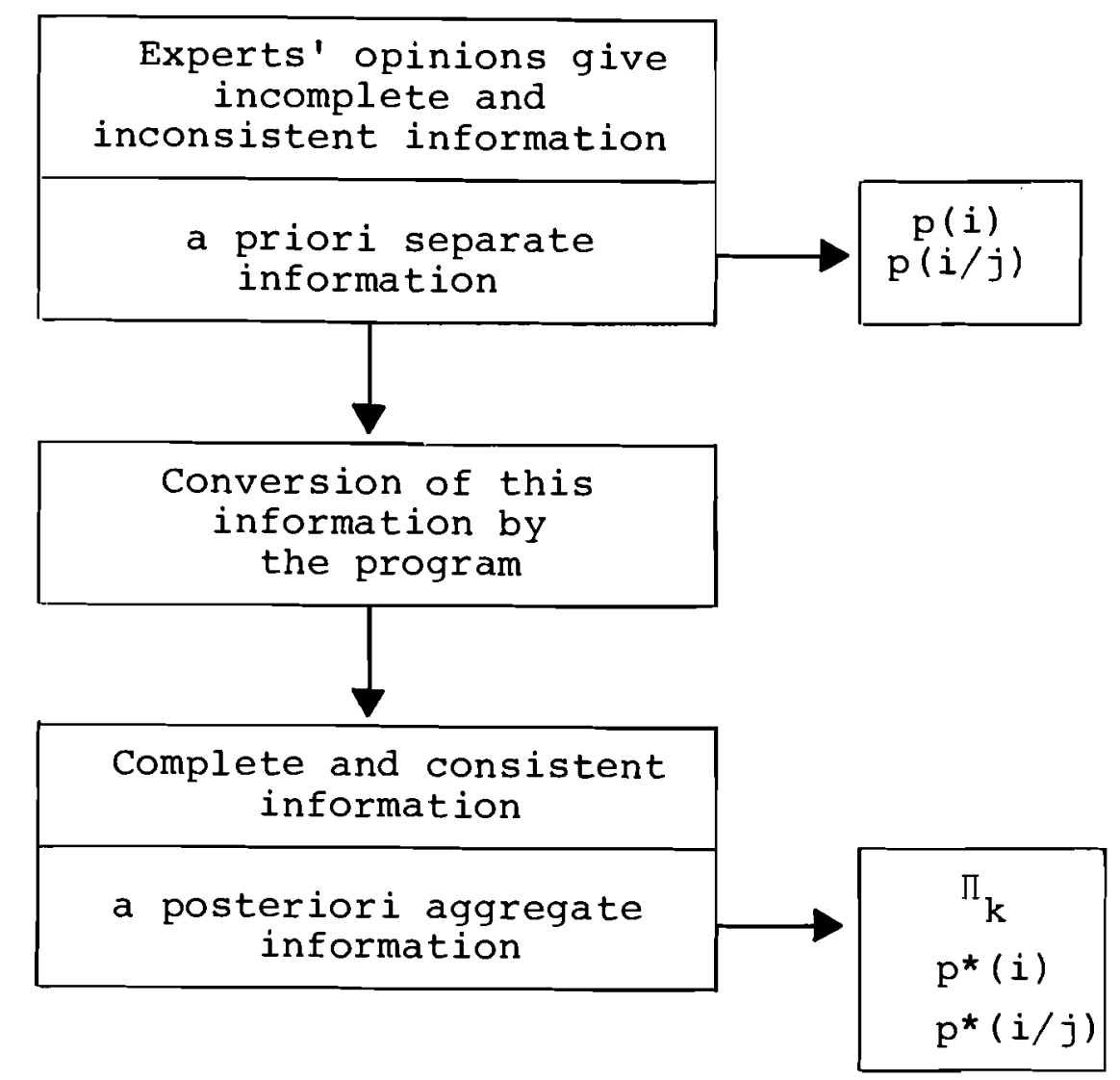

II. Overview on the Developed Models in the World

2.1. Overview and Classification of Energy Models

Last summer IIASA (International Institute for Applied Systems Analysis) organized a meeting on this theme [16] and also published the first issue [3] of an annual review devoted to the energy models currently being developed all over the world.

To bring together what was discussed during this meeting with an analysis of this overview, two major points must be made:

1) if we put away the very specific models developed by private utilities, there are few models which permit study of the global energy problems either at a national or international level; and 
2) the institutions and the links between universities and energy agencies have a fundamental role to play for the quality and the realistic aspects of the models.

Let us have a quick look at the review and the classification adopted at IIASA.

\section{1.a. Standard Summary of the Model}

Each studied model has been summarized in the standard form in Figure 2. Item 1 contains the bibliographical information: name of author, date, localization, etc. Item 2 describes the subject studied and the goals of the model. Item 3 gives a general idea of the complex interactions within the system described.

After this general description of the system studied and the goals aimed at by the author, the following two items "Modelling techniques" and "Input data" try to make a clear distinction between what is endogenous and what is exogeneous. The item "Modelling techniques" endeavors to give a description of all logical aspects of the model. The mathematical aspects are not detailed; only the main concepts which explain the internal structure of the mathematical representation are drawn up.

The item "Output data" only indicates the kind of results given by the model. The quantitative values supplied by each model are often too large to be incorporated in such a summary. Finally, the item "Observations" is mainly devoted to possible future developments of the models.

\subsection{Classification of the Models}

The classification of the models adopted divides the models into six classes $(A, B, \ldots, F)$. The first distribution is made between models which study energy problems either at a national or at an international level. Then a second classification is made for distinguishing the models which 


\begin{tabular}{|c|c|c|}
\hline \multicolumn{2}{|c|}{ The Model } & $\begin{array}{l}\text { Kenneth Hoffman, } 1972 \text { Brookhaven National Lahoratory, Upton, L.I., N.Y, } \\
\text { Planning Framework for Energy System Planning. }\end{array}$ \\
\hline \multicolumn{2}{|c|}{$\begin{array}{l}\text { Subject } \\
\text { and Goal }\end{array}$} & $\begin{array}{l}\text { Optimal technical structure of the US energy system. The model reflects a wide } \\
\text { range of energy technologies and interfuel substitutability. It traces paths from } \\
\text { primary consumption to final demand for each type of tuel. }\end{array}$ \\
\hline \multicolumn{2}{|c|}{$\begin{array}{l}\text { System } \\
\text { Described }\end{array}$} & $\begin{array}{l}\text { This model is concerned with the substitution of different fuels at the level of } \\
\text { disaggregated demand and supply. In addition, it estimates the volume of each type } \\
\text { of pollutant produced by the energy system. }\end{array}$ \\
\hline \multirow{2}{*}{ Area } & Time & $\begin{array}{l}\text { Static model for a particular point in time (has been applied to the years } 1985 \text { and } \\
2000) \text {. }\end{array}$ \\
\hline & Space & USA as a whole. \\
\hline \multicolumn{2}{|c|}{$\begin{array}{l}\text { Modelling } \\
\text { Techniques }\end{array}$} & $\begin{array}{l}\text { Optimization model using linear programming. The model provides a feasible path } \\
\text { between n=13 exogenous supply categories and m=15 exogenous demand categories. The } \\
\text { objective function is the minimized solution of the present cost of the possible } \\
\text { paths. Three constraints must be satisfied: the level of each kind of demand, the } \\
\text { possibility of each kind of supply system, and the levels of the different pollu- } \\
\text { tions. An expanded model is under development with } 27 \text { supply categories and } 22 \\
\text { demand categories. }\end{array}$ \\
\hline \multicolumn{2}{|c|}{$\begin{array}{r}\text { Input Data } \\
\text { Physical }\end{array}$} & 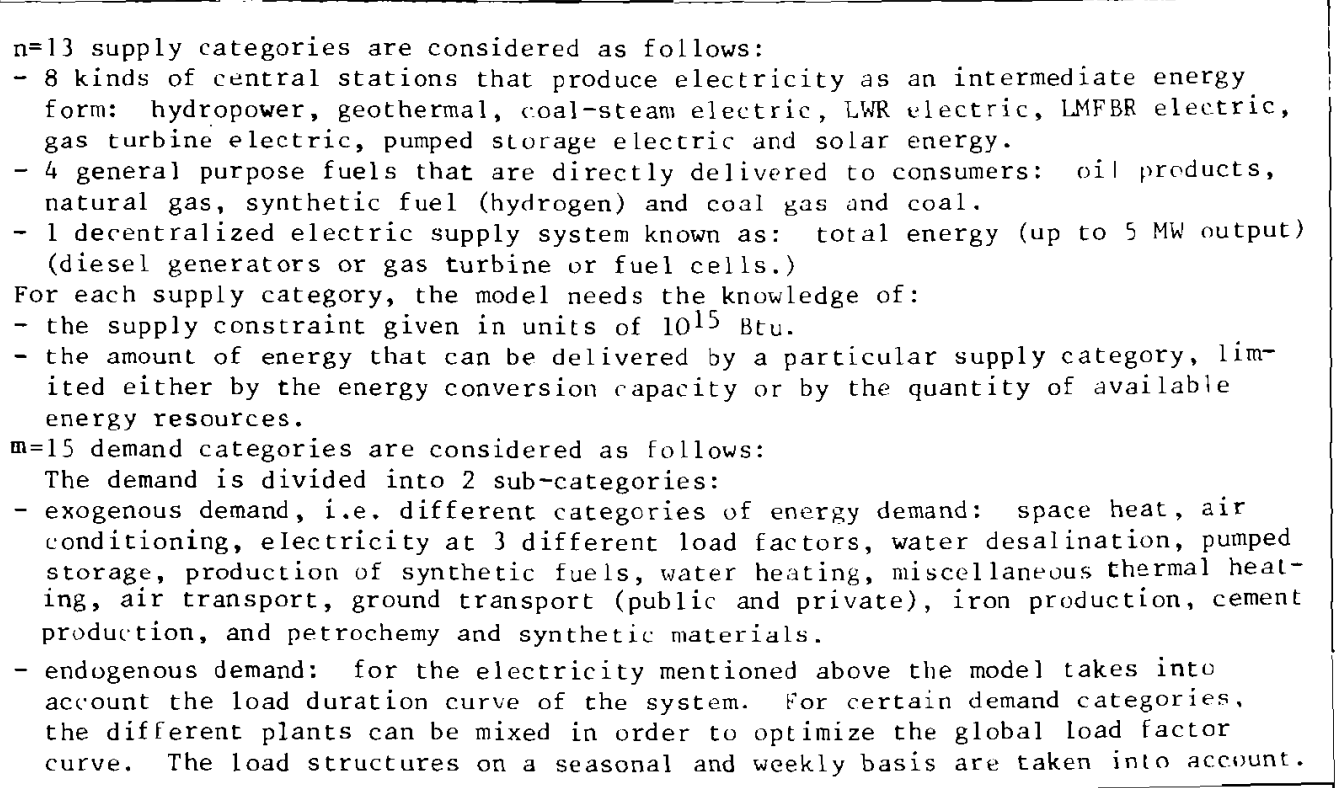 \\
\hline \multicolumn{2}{|c|}{ Ecological } & $\begin{array}{l}\text { The model incorporates air pollutants and other wastes generated by energy conver- } \\
\text { sion activities that are proportional to the amount of energy delivered: } \mathrm{CO}_{2}, \mathrm{CO} \text {, } \\
\mathrm{SO}_{2} \text {, No, particulates, hydrocarbon, radioactive wastes and thermal wastes, other } \\
\text { pol } 1 \text { utants and land use will be incorporated in the expanded model. }\end{array}$ \\
\hline \multicolumn{2}{|c|}{ Ficonomic } & $\begin{array}{l}\text { The coefficients of cost in the objective function reflect the necessary cust of } \\
\text { the facilities used in the energy supply system as well as fuel and other operating } \\
\text { costs. The necessary cost of capital for the tectric supply category is a function } \\
\text { of the plant load factor which is also a function of each specific demand iategory. }\end{array}$ \\
\hline \multicolumn{2}{|c|}{$\begin{array}{l}\text { Output Datil } \\
\text { Physical }\end{array}$} & $\begin{array}{l}\text { The model gives for a specified level of each demand the optimal utilization of the } \\
\text { different available supply systems. }\end{array}$ \\
\hline \multicolumn{2}{|c|}{ Economic } & $\begin{array}{l}\text { The model gives the total cost of the energy system but the resulting optimal path } \\
\text { is greatly dependent on the different input costs. }\end{array}$ \\
\hline \multicolumn{2}{|c|}{ Ecologiral } & The model gives the volume of the different polluting emissions. \\
\hline \multicolumn{2}{|c|}{ bbservations } & $\begin{array}{l}\text { - This model is static; it can be used only for one year. For that year it is neces- } \\
\text { sary w know the demand and the supply categories. The level of the different kinds } \\
\text { of demands can be obtained by using an input-output model. } \\
\text { - The price electicity of demand is not taken into account in the current model but } \\
\text { is being added to the expanded model. } \\
\text { - Dynamization of the model is being studied. }\end{array}$ \\
\hline
\end{tabular}

Sumary reviewed by the author of the model. 
only look at the energy problems and the models which link the energy area with global economics. In the first group another subdivision is used for separating models which take into account one energy field from models which investigate different energy sources.

Model Classification

\begin{tabular}{|l|c|c|c|}
\hline \multicolumn{2}{|c|}{ Areas of Application } & National & International \\
\hline & $\begin{array}{c}\text { one kind } \\
\text { of fuel }\end{array}$ & A & B \\
$\begin{array}{l}\text { Energy system } \\
\text { (energy is the } \\
\text { main problem) }\end{array}$ & $\begin{array}{l}\text { several } \\
\text { kinds of } \\
\text { fuel }\end{array}$ & C & $(66 \%)$ \\
\cline { 2 - 4 } & $\begin{array}{l}(23 \%) \\
\text { Linkage between energy and } \\
\text { general economy }\end{array}$ & E & D \\
\hline
\end{tabular}

In the group A (one energy form at the level of a country) we found a tremendous number of models (approximately one-half of the seventy models analyzed in the review). It is practically impossible to give a general overview of them because one finds that in all the industrial firm models each author aims at a specific goal. It would not be productive to review these models, since each has its own special target.

In the group $B$ (one energy form at the international level) one finds--and it was easy to forecast because of the present fuel-oil problem--a large number of models studying the market of this fuel.

The models developed by R.J. Deam [4] of Queen Mary College, UK, and by $H$. Houthakker and M. Kennedy [11] of Harvard University, USA, seem to be the most efficient. In both models, the world models.

${ }^{6}$ Percent of models in this class among the seventy analyzed 
market of fuel oil is divided into a certain number of regions where production, transport, and refining are taken into account. The Deam model used linear programming in order to minimize the total expenditure for a given level of the demand. The Houthakker and Kennedy model simulated a market that the authors supposed optimal and it is described by using equations which can be interpreted as first order conditions of a quadratic programming problem describing a competitive market. These two models are still being developed but could nevertheless be used now for studying different policies.

Group C (different forms of energy for a given country) is as important in number (23\% of the analyzed models) as it is in theme. The group essentially studies the possibilities of substitution between different forms of energy either at the primary supply side or at the final use side. One of the most relevant models in this category is that of Dr. K. Hoffman (see Figure 2 and [9]) of the Brookhaven National Laboratory, USA, using linear programming. For a given year it studies the best linkage between thirteen given supply sectors and fifteen given demand sectors. The criterion is the minimization of the total expenditure. The constraints are essentially related to the demand level to be satisfied, to the level of supply and to the level of pollution $\left(\mathrm{SO}_{\mathrm{x}}, \mathrm{CO}_{\mathrm{x}}, \mathrm{NO}_{\mathrm{x}}\right.$ particulates, radioactive wastes, and thermal wastes). Dr. Hoffman is actually working on a dynamization of his model.

Linked to this group is the work being carried on by Prof. W. Häfele and his team at IIASA for the study of the transition from fossil to other fuels in a given economy. The first publication from this work came out in June 1974 and is entitled "Strategies for a Transition from Fossil to Nuclear Fuels" by W. Häfele and A.S. Manne [7]. The objective is to minimize (by linear programming) the present value of costs incurred annually during each period (three years) over a seventy-five year horizon. It is interesting to note that two kinds of models have been developed where either 
the final demands for energy are taken to be exogenous, or these demands are endogenous since they depend upon the costs of supply. In the model where the demands are responsive to price, the objective function is the maximization of the money value of consumers' utility less the costs of meeting the final demand. (If $q$ is the quantity of energy, then the utility function of the consumer is $u(q)=a q^{b}+c$, where $a, b, c$, are estimated through a series of assumptions concerning the demand curves.)

It is not useful to speak in detail of the models of group D (different fuels at international level) and group $F$ (energy inside global and international models) because very few models have been developed in these areas at this time. Even if energy is a major problem, it is only one problem within a complex system that humanity has to forecast and to solve. For this reason, it is logical that the energy problem is only part of the global and world studies. The club of Rome initiated such studies, and now five or six such works are in progress around the world. Unfortunately, even in the most elaborated way, the energy area is often only quickly studied.

Nevertheless, three of these studies are interesting to note. The first is the well-known "World Model" of Mesarovic (USA) and Pestel (FRG) [14], the second, the socalled "Latin American Model" (Fundacion Bariloche, Argentina [1]. The Mesarovic-Pestel model mainly tries to investigate the results of various alternative policies, while, on the other hand, the Bariloche model has an explicit, normative goal, namely to narrow the gap between $r i c h$ and poor countries.

The third study to be mentioned is that of Prof. L.R. Klein (USA) [13]. Prof. Klein is currently developing a model which links different national models using external trade relations.

Now let us look at group $\mathrm{E}$ where energy is studied by linkage to other national economic problems. Without any doubt, this group of models is the most important even with 
most of the models still being developed. The energy area has such a great impact on all other economic problems that the linkage between energy and economics seems essential. Right now, a number of models in this field are being worked on from either the qualitative or the quantitative point of view. Even though the qualitative approaches seem very fruitful for long-term investigations, I shall not mention them now.

In the quantitative aspect of this problem, I should especially like to mention the work done by Prof. Dale Jorgenson, Harvard University, USA [12], who dynamized the input-output matrix in using production functions which include both technical progress and price effects. This study is a good one to narrow the energy demand aspect which, in most of the other models, is either exogenously treated or endogenously integrated in using simple elasticity coefficients that many authors are beginning to consider not very efficient for forecasting problems.

The Jorgenson model is formulated for the analysis of interrelationships between energy utilization and economic activity. The most distinctive feature of the model is the incorporation of demand and supply for energy into a single analytical framework. A second important innovation is the analysis of the relationship between energy demand and supply and US economic growth.

The first component of the Jorgenson Energy Model is the Long-Term Growth Model which provides projections of aggregate US consumption, investment, government final demand, and the prices of primary input: labor and capital. The model includes production and household sectors of the US economy as endogenous components, and the government and foreign sectors as exogenous. The model determines demand and supply for consumption goods, investment goods, capital services, and labor services by means of simulated market processes. Both prices and quantities of final output and factor input are endogenous to the model. 
The Long-Term Growth Model is made dynamic by links between investment, capital stock, and productive capacity, and by the reaction of the household sector to past as well as present incomes and prices.

The second component of the Jorgenson Energy Model is based upon an inter-industry structure incorporating transactions not only between producers and final users, but also between producer purchases of primary inputs and transactions between different production sectors themselves. The basic element of the model is a model of producer behavior, one for each of the producing sectors, that determines the sector input requirements and output price on the basis of other prices, levels of technological efficiency, and production coefficients. This sectoral information is then integrated, and the sectoral interdependencies analyzed by means of the input-output technique.

Briefly, input-output analysis sets up requirements for input purchases per unit of output for each sector, and then brings the transactions pattern into consistency by requiring that production levels be such that a specified mix of final output can be satisfied with the total supply and demand of each sector's output being equal. The novel feature of the energy model is that the input-output coefficients, which specify the input requirements per unit of sectoral output, can vary in response to changes in relative price and technological efficiencies. This variation allows substitution between inputs, within the limits of production technology, in response to changes in prices and availabilities, and it also allows each sector's efficiency level to be reflected in the amount of inputs required per unit of output.

The actual solution of the model proceeds along the following steps:

a) the Long-Term Growth Model provides prices of the primary inputs and the total final demands for consumption, investment and government spending; 
b) the energy model disaggregates the final demand totals into final demand for each of the producing sectors;

c) prices are estimated on the basis of primary input prices, technology levels, production coefficients and the models of producer behavior;

d) the models of producer behavior are also used to calculate, using these prices, technology levels, and production coefficients, the input-output coefficients specifying the input patterns from the twelve supplying sectors into each of the nine producing sectors;

e) the final demand requirements for each sector are combined with the input-output coefficients to derive the total required output from each sector as well as the inter-industry sales, the purchases of primary inputs and the sales to final users.

Inter-industry or producing sectors are:

1) agriculture, non-fuel mining, construction;

2) manufacturing, excluding petroleum products;

3) transportation;

4) communications, trade, services;

5) coal mining;

6) crude petroleum and natural gas;

7) petroleum refining and related industries;

8) electric utilities;

9) gas utilities.

Primary input sectors are:

10) imports;

11) capital;

12) labor.

Final demand sectors are:

13) consumption;

14) investment;

15) government;

16) exports. 
Conclusion

As a conclusion I should like to briefly highlight major, difficult problems related to the formulation of energy demand and its linkage to the global economy.

A. The first problem deals with exogenous versus endogenous representation of the demand of energy modelling.

If the exogenous concept of demand is used a great deal, it should nevertheless be looked at as some kind of first approximation that you may find useful. Only if you concentrate on something other than demand may exogenous notions of demand be useful as for example in investment models of private utilities.

B. The purpose of the second remark deals with the structural relation between GNP and energy consumption.

Up to now a lot of global energy forecasts have been made in using the "good" mathematical correlation between GNP and energy consumption. Two remarks can be made:

1) you shift the problem of energy demand to the forecast of GNP which is not easy to solve;

2) the structural relation between GNP and energy has never been really proved, and furthermore, if you disaggregate, for example, the industrial sector into production subsectors such as glass, steel, and so on, the correlation between energy consumption and value added in each sector is never more evident.

Three questions now come to mind:

a) Is the "good" correlation between GNP and energy not only a mathematical result due to two quantities which had growth at a constant rate up to now? Are we authorized to use the result in new forecasting in societies where a lot of things change in the economic relations? 
b) Could we consider that GNP is a good approximation of income which is a major variable in the consumption function? Many authors have already drawn attention to this point; a famous example likens the increase in GNP to being blocked in a traffic jam with your car: the motor is running but the car is not moving.

c) Could we continue to use trend projections where these appear to be complete changes in different economic relationships?

C. The third remark deals with the next variable that one would introduce after income. The price of energy or of its components.

There are general agreements on the fact that responses to price are not instantaneous. But how to measure the fact that the modifications of habit take some time is a problem. As long as the consumer thinks that he still wants the same amount of energy when it has become more expensive, he will find that he can only have less of something else. When he becomes aware of this, he will change his habits. But in addition, there is his energy-using equipment: e.g. the big car. It takes a few years before the big car is worn out, that is to say, before he is ready to substitute a smaller car for the bigger one. Therefore we must regard this demand relationship as having a time-lag structure to it, but the data in this field are very poor at this time.

I shall stop the list of the not well-known questions related to the problem of energy demand here. In this field such a great number of questions have to be studied, and a full seminar could be devoted to it.

As a last consideration I shall briefly report on the work being done at IIASA on this subject. The energy demand research program tries to highlight the problem from two approaches :

1) The first approach [16] consists of an econometric model of the world energy system where the efficiency of the market forces to determine the prices of energy resources are 
carefully studied along with the efficient allocation of energy resources over time. For the time being, the world is broken into five regions; the resource variables are: petroleum, oil shale, coal, nuclear fuel, and natural gas. Demand is broken into the following categories: electricity, process heat, residential heat, substitutable and nonsubstitutable transport. Many new technological processes are included, for example: gasification and liquefaction of coal, breeder reactors, hydrogen and electric automobile, and so on.

In order to avoid the fixing of a horizon on the model, the concept of backstop technology is introduced, that is a set of processes which:

a) are capable of meeting the demand requirement, and

b) have virtually an infinite resource.

The modelling technique used is linear programming.

2) The goal of the second approach consists of building normative scenarios which link the level of energy consumption with the global economic development of different "model societies." For that purpose the work presently developing is being pursued along two lines:

a) The first deals with the qualitative (and when possible quantitative) research on the most relevant parameters that have to be taken into account for linking the energy area with the other parts of an economy. Two methods are studied: one is a factor analysis whose goal is to bring together a group of countries versus their main economic variables; the other is to develop a method [6] to try by means of a cross-impact matrix ${ }^{7}$ to $\mathrm{fix}$ an order of effectiveness on the different parameters. The research on the main parameters will be used later to build scenarios in the same way as briefly described above. 
b) The second line of research is an engineering approach very close to the problem of energy budget and energy content in different goods: how much energy is needed for producing a car, a house, or a meal of $3000 \mathrm{Kcal}$, etc? This basic information will be used later on to feed the qualitative scenarios.

\section{${ }^{7}$ With the help of experts one has first to define the} most possible exhaustive list of parameters having an impact on energy demand. Let us say: $a, b, c, \ldots, k$. Most of them have mutual influence which could be represented by a matrix as :

\begin{tabular}{|c|c|c|c|c|c|c|}
\hline & $a$ & $b$ & C & $\mathrm{d}$ & I & -k \\
\hline$a$ & & 0 & 1 & 0 & 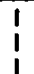 & 1 \\
\hline$b$ & 1 & & 0 & 1 & i & 1 \\
\hline C & 0 & 1 & & & ! & \\
\hline $\mathrm{d}$ & & & 1 & & i & \\
\hline $\mathrm{k}$ & & & & & $i$ & \\
\hline
\end{tabular}

where:

0 means, for example, that (a) has no influence on
(b); and

1 means, for example, that (a) has an influence on (C).

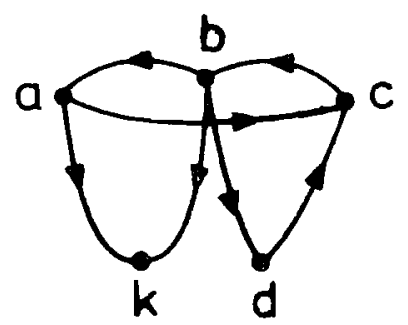

This matrix can be represented by a graph where the relations between two parameters are drawn by oriented lines. The idea is then to classify the parameters either in counting the number of lines that are going through there or the number of loops in which they are incorporated. For example, if (a) belongs to six loops when (d) belongs only to one; it is quite obvious that the parameter (a) is more important than (d) and so on. 


\section{$\underline{\text { References }}$}

[1] Bariloch Foundation. "Latin American World Model." Buenos Aires, 1974 .

[2] Breton, A. "Application de la Théorie de la Commande Optimale aux Problèmes de Choix des Equipements de Production." Etudes Economiques Générales E.D.F., Paris, 1972 .

[3] Charpentier, J.-P. With the collaboration of Elsinghorst (FRG), Girod (France), Treitel (France), and Voss (FRG). "Review of Energy Models." IIASA, Laxenburg, Austria, RR-74-10, May 1974 .

[4] Deam, R.J. "World Energy Supply Analysis." Energy Research Unit, Queen Mary College, University of London, 1973.

[5] Duperrin, J.-C. and M. Godet. "A Method for Constructing and Ranking Forecasting Scenarios." Montrouge, METRA Group, 1974 .

[6] Duperrin, J.-C. and M. Godet. "Systèmes et Matrices d'Impact Croisés." Rapport Economique CEA-R-4541, Paris, 1973.

[7] Häfele, W. and A.S. Manne. "Strategies for a Transition from Fossil to Nuclear Fuels." IIASA, Laxenburg, Austria, RR-74-7, 1974 .

[8] Herendeen, R.A. "Use of Input-Output Analysis to Determine the Energy Cost of Goods and Services," Energy Demand Conservation and Institutional Problems."

Michael S. Macrakis, ed., MIT Press Cambridge, Mass., 1974, pp. 141-158.

[9] Hoffman, K. "A Unified Planning Framework for Energy Systems Planning." Upton, N.Y., Brookhaven National Laboratory, 1972 .

[10] Houthakker, H. and M. Kennedy. "Demand for Energy." Cambridge, Mass., Harvard University Press, 1974.

[11] Houthakker, H. and M. Kennedy. "The World Petroleum Model." Cambridge, Mass., Harvard, 1974.

[12] Jorgenson, D. and E. Hudson. "U.S. Energy Policy and Economic Growth 1975-2000." Cambridge, Mass., Harvard and Data Resources, 1974.

[13] Klein, L.R. "International Linkage of National Economic Models." International Study Group. The Link System, R.J. Ball, ed., Amsterdam, North Holland, 1973. 
[14] Mesarovic, M. and E. Pestel. "Multilevel Regionalized World Model." Case Western Reserve University, Cleveland, Ohio, Technische Universität, Hannover, FRG, 1974 .

[15] Nordhaus, w. "The Allocation of Energy Resources." Unpublished Manuscript. New Haven, Conn., Yale University and IIASA, Laxenburg, Austria, 1974.

[16] "Proceedings of the IIASA Working Seminar on Energy Modelling, May 28-29, 1974." IIASA, Laxenburg, Austria, CP-74-3, 1974 .

[17] Puiseux, L. "Prévoir la Demand d'Electricité." Thèse de Doctorat. Ecole des Hautes Etudes, Paris, April 1973. 